\title{
Movilidad geográfica de los rumanos \\ (Estructura territorial de las migraciones interiores \\ en España)*
}

\author{
RAFAEL Viruela MarTíneZ \\ Departamento de Geografía \\ Universidad de Valencia \\ Rafael.Viruela-Martinez@uv.es
}

Recibido: 18.06 .2009

Aceptado: 24.02 .2010

\section{INTRODUCCIÓN: LA ESTADÍSTICA DE VARIACIONES RESIDENCIALES Y LA MOVILIDAD INTERIOR DE LA POBLACIÓN EXTRANJERA}

La movilidad geográfica de los extranjeros no ha merecido en España la atención que se le da en países de mayor tradición inmigratoria, como Estados Unidos o Canadá. No obstante, desde los primeros trabajos realizados en nuestro país por Joaquín Recaño (2002), son cada vez más los autores interesados en las migraciones interiores, la mayoría geógrafos. Entre las conclusiones de sus investigaciones, destaca el papel creciente de la población extranjera en los movimientos migratorios internos. En efecto, hace diez años realizaron menos de 40.000 cambios de residencia, el 4,2\% del total, y en 2007 más de medio millón, lo que supone el $30 \%$. Sus pautas migratorias difieren en intensidad y estructura espacial de las de los españoles (Recaño, 2006). Asimismo, hay una gran diversidad de patrones migratorios según la nacionalidad de los extranjeros. La movilidad es más intensa en colectivos que han llegado en fecha reciente y han incrementado sus efectivos de forma rápida (Recaño, 2002; Pumares, 2005). Los desplazamientos interiores se relacionan fundamentalmente con el mercado

* El autor desea manifestar su agradecimiento a Marcos Robles Herrero, oficial de laboratorio en el Servicio Central de Soporte a la Investigación Experimental (SCSIE) de la Universidad de Valencia, por su inestimable colaboración en la tabulación de los ficheros de microdatos de la Estadística de Variaciones Residenciales, y a Catherine Andrés Langa, miembro de la Unidad de Investigación «Estudios del Territorio, Paisaje y Patrimonio» (ESTEPA), responsable del diseño gráfico. 
de trabajo y de la vivienda (Pumares, García y Asensio, 2006) y modifican continuamente la distribución geográfica de la población extranjera residente en España (García, 2005).

La Estadística de Variaciones Residenciales (EVR) es la fuente estadística más adecuada para analizar las migraciones interiores en España. Se elabora con las altas y bajas registradas en el Padrón de Habitantes y contabiliza los cambios de municipio de residencia a lo largo de un año. Los inmigrantes, incluso los que se encuentran en situación irregular, han mostrado una fuerte propensión al empadronamiento en los últimos años ya que es un elemento clave para acceder a los servicios sanitarios y educativos y en los procedimientos de regularización. No obstante, tal como señala el profesor Arango (2004), hay motivos para albergar dudas acerca de la exactitud del Padrón, en unos casos por sobreestimación del número de inmigrantes (inscripciones anticipadas o duplicadas), en otros por subestimación. Miguel Pajares (2007), autor de un minucioso trabajo sobre los inmigrantes rumanos en Cataluña, señala que muchos de ellos no se empadronan en los primeros años de su establecimiento ${ }^{1}$. Además, en el tema que nos ocupa, no se registran todos los cambios de residencia y algunos se declaran con bastantes meses de retraso.

En la EVR la unidad de medida es la migración y no el migrante. Una misma persona puede realizar varias migraciones en un periodo determinado y todas ellas quedan registradas en la estadística. Las variables que incluye son la nacionalidad, el sexo, la fecha y el lugar de nacimiento, la fecha de la variación (del desplazamiento), la localidad y provincia de baja (origen) y las de alta (destino), así como el tamaño demográfico de los municipios. Parte de la información está elaborada y disponible en la página Web del Instituto Nacional de Estadística, que ha puesto a disposición de los investigadores el fichero de microdatos que permite el estudio detallado de las migraciones. Los datos son anónimos, es decir, no hay ninguna variable que permita identificar a las personas, lo que no ha sido obstáculo para que algunos autores realicen estimaciones de las variaciones residenciales atribuibles al mismo individuo (Martí y Ródenas, 2006). Para demostrar la calidad de la información aportada por la EVR, otros autores la comparan con datos de la Seguridad Social relativos a la provincia de alta inicial y la provincia de alta actual de los trabajadores extranjeros, con resultados satisfactorios, demostrando que hay una relación estrecha entre la movilidad geográfica y la movilidad laboral (Pumares, García y Asensio, 2006).

${ }^{1}$ Los motivos del subregistro son diversos. Unos no se empadronan porque realizan continuas idas y venidas entre el lugar de origen y el de destino; otros porque viven con compatriotas y el titular del alquiler se niega a empadronarles por miedo a que se sepa que hay mucha gente en el mismo domicilio. Hay casos en que son los mismos ayuntamientos los que se muestran reticentes al empadronamiento. Entre los ciudadanos de nacionalidad rumana, los miembros de la minoría gitana sí consideran conveniente inscribirse en el padrón sobre todo para la obtención de la tarjeta sanitaria (Macías, 2007; Pajares, 2007). 
El objetivo de este artículo es analizar la estructura territorial de las migraciones interiores de los rumanos en España entre 2001 y 2007 a partir de los datos proporcionados por la EVR. Como ya se ha comentado, es la fuente más precisa sobre los movimientos migratorios, pero con limitaciones ya que, por ejemplo, no recoge datos relativos a la actividad económica de las personas. Esta carencia se puede subsanar con la información que proporcionan otras fuentes básicas: la Seguridad Social, la Encuesta de Población Activa o la Encuesta Nacional de Inmigrantes de 2007 (Reher, 2008; Reher y Requena, 2008) y, en lo que respecta al colectivo rumano, la encuesta realizada en cuatro municipios de la Comunidad de Madrid en septiembre de 2008 (Sandu, 2009). No obstante, teniendo en cuenta el corto espacio de un artículo y los objetivos del mismo, se ha optado por utilizar la EVR, cuyos resultados se completan con los obtenidos en varias investigaciones empíricas que, con una metodología cualitativa, indagan en los procesos migratorios de los rumanos. Antes de continuar, interesa una breve presentación de la población rumana en España, destacando los aspectos más directamente relacionados con la movilidad interior.

\section{EL VOLUMEN DE POBLACIÓN RUMANA Y SU DISTRIBUCIÓN GEOGRÁFICA}

A principios de 2008, los rumanos empadronados en los municipios españoles eran 731.806 y ocupaban el primer puesto entre la población extranjera que reside en España ${ }^{2}$ (el 14\% del total). Hace una década contaban poco más de 3.000 efectivos (el $0,4 \%$ de los extranjeros en 1999) y ni siquiera se encontraban entre los 30 primeros. En el rápido y espectacular aumento de la inmigración rumana (figura 1) confluyen varios factores ${ }^{3}$ : las dificultades para establecerse en otros países de su preferencia, el rápido fortalecimiento de las cadenas y redes migratorias construidas sobre vínculos familiares o de proximidad geográfica o social (vecindad, etnia, religión), la favorable acogida de la sociedad receptora e incluso la afinidad cultural ligada a la lengua románica. La facilidad de movimientos por el interior del espacio Schengen, primero con la exención de visado (el 1 de enero de 2002) y hace poco con la incorporación de Rumania en la Unión Europea (el 1 de enero de 2007), ha sido un estímulo importante.

La evolución de los residentes rumanos revela que en un porcentaje alto son personas que llevan muy poco tiempo viviendo en España. Circunstancia especialmente relevante porque, como señala Recaño (2002), la propensión a cambiar de residencia es mayor entre los recién llegados. Más todavía en una población que como la rumana cuenta con experiencia en la movilidad, tanto

${ }^{2}$ Según los resultados provisionales del último Padrón de Habitantes, a 1 de enero de 2009, la cifra ascendía a 796.576 residentes.

${ }^{3}$ Una relación detallada de los factores que han contribuido a esta corriente migratoria se puede consultar en Viruela (2008). 


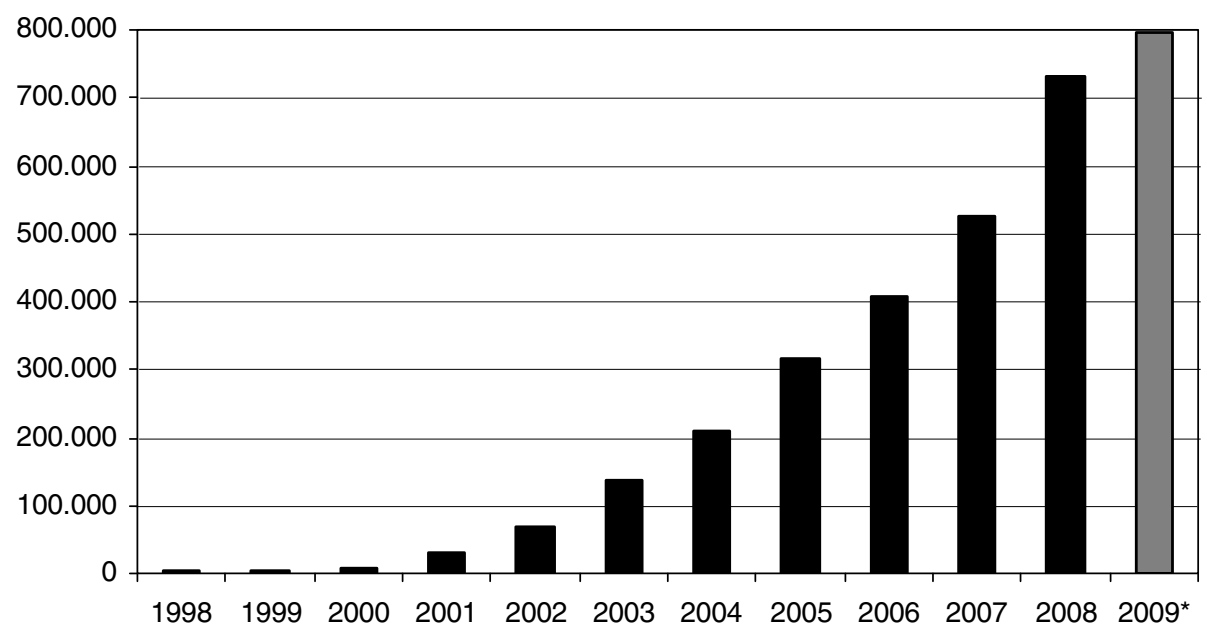

Fuente: INE, Padrón de Habitantes [www.ine.es]

* Datos provisionales.

Figura 1. Población rumana residente en España (1998-2008).

dentro de su país (Cristescu y Muntele, 2007) como en el exterior, tanteando diferentes destinos hasta encontrar el más apropiado e instalándose en la migración circulatoria, con continuas idas y venidas entre el lugar de origen y el de destino. Experiencia migratoria que se ha consolidado en las dos últimas décadas y constituye una de las señas de identidad de la emigración rumana (Diminescu, 2003; Potot, 2007).

Como en toda migración económica, predominan los jóvenes y adultos en los primeros grupos de edad laboral. A la juventud, los rumanos añaden una estructura bastante equilibrada en cuanto a sexo, sobre todo en fecha reciente (en 2001 las mujeres representaban el 39\% y en 2008 alcanzaban el 46\% del total), lo que sugiere una migración con cierto componente familiar (Domingo, 2008). Conviene recordar que parte de los inmigrantes rumanos (entre el 5 y el $10 \%$ del total) son de etnia gitana (Macías, 2005; Pajares, 2007) y muestran mayor movilidad que sus compatriotas (Macías, 2007).

En vísperas del ingreso de Rumania en la UE, había en España más rumanos en situación irregular que residentes legales ${ }^{4}$. La irregularidad administrativa no

${ }^{4}$ Los rumanos aprovecharon la exención de visado, en 2002, para entrar en España de forma legal como turistas. La mayoría ha permanecido de forma irregular a la espera de un proceso extraordinario de regularización. Desde enero de 2007 pueden entrar y residir en España sin problemas, pero no trabajar como asalariados durante los dos primeros años, a no ser que ya lo estuvieran haciendo o que vinieran con un contrato en origen. 
ha impedido su rápida incorporación al mercado de trabajo, en la agricultura, la construcción, el servicio doméstico (cuidado de personas dependientes y limpieza), la hostelería, etc. Sectores en los que también trabajan los miembros de la minoría rom, que se ocupan más en actividades marginales: venta de periódicos, limpieza de parabrisas, venta de pañuelos, recogida y venta de chatarra o mendicidad (Macías, 2007; Martínez Ibars, 2008). Muchos rumanos han permanecido en situación irregular y en la economía sumergida durante años. Una etapa en la que los periodos de intensa actividad se alternan con otros de desempleo. La situación mejora tras un proceso extraordinario de regularización, que les permite incorporarse al mercado de trabajo formal. Los programas de regularización y el recién adquirido estatus de ciudadanos comunitarios han ofrecido a los rumanos la oportunidad de movilidad geográfica.

La distribución geográfica de la población rumana se caracteriza por la concentración en unas pocas provincias y ciudades. Según los resultados del Padrón de Habitantes de 2008 (figura 2), el 26\% reside en Madrid y el 36,4\% en el litoral mediterráneo. En el interior de la península, Lérida, Zaragoza y las pro-

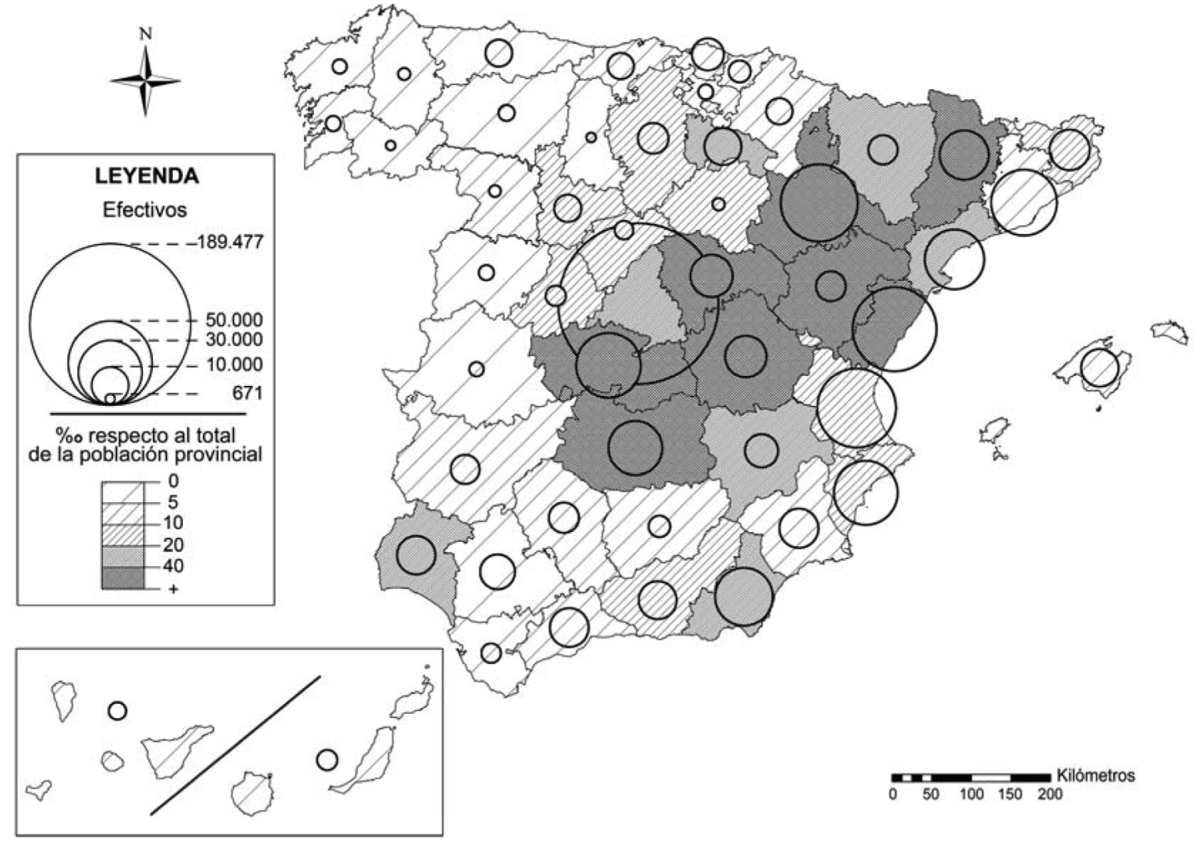

Fuente: INE, Padrón de Habitantes [www.ine.es].

En el mapa no se representan las ciudades norteafricanas de Ceuta y Melilla, que contaban con 8 residentes de nacionalidad rumana cada una.

Figura 2. Distribución geográfica de la población rumana, a 1 de enero de 2008. 
Cuadro 1. Número de municipios con presencia de extranjeros de cuatro nacionalidades

\begin{tabular}{|l|c|c|c|c|c|c|}
\hline & \multicolumn{2}{|c|}{2001} & \multicolumn{2}{c|}{2005} & \multicolumn{2}{c|}{2008} \\
\hline & Municipios & \% & Municipios & \% & Municipios & \% \\
\hline Marroquíes & 3.018 & 37,2 & 3.781 & 46,6 & 4.219 & 52,0 \\
\hline Ecuatorianos & 2.394 & 29,5 & 3.262 & 40,2 & 3.070 & 37,5 \\
\hline Rumanos & 1.690 & 20,8 & 3.831 & 47,2 & 5.049 & 62,2 \\
\hline Búlgaros & 1.229 & 15,2 & 2.435 & 26,3 & 3.009 & 37,1 \\
\hline Municipios de España & 8.108 & & 8.109 & & 8.112 & \\
\hline
\end{tabular}

Fuente: INE, Censo de Población 2001 (noviembre) y Padrón de Habitantes (enero) [www.ine.es]. Elaboración propia.

Porcentaje con respecto al total de municipios de España.

vincias de Castilla-La Mancha reúnen entre todas poco más del 20\%. Es aquí donde los rumanos alcanzan mayor importancia relativa (más de 40 efectivos por cada 1.000 habitantes), a cierta distancia de Castellón (con 87). Los valores absolutos y relativos disminuyen considerablemente en las provincias más occidentales (excepto Huelva), en el litoral norte y en las islas Canarias.

Las principales áreas de asentamiento en España siguen siendo las mismas que en 2001 (Reques y Cos, 2004; Viruela, 2008), pero la dimensión alcanzada por esta corriente inmigratoria ha generalizado la presencia de rumanos por buena parte del territorio. En efecto, en 2002, los rumanos ocupaban la primera posición entre la población extranjera sólo en la provincia de Castellón (Viruela, 2006); en la actualidad, es el colectivo con mayor número de representantes en veintidós provincias y ocupan la segunda posición en otras diez. En noviembre de 2001, el Censo de Población registró la presencia de rumanos en $1.690 \mathrm{mu}-$ nicipios. Siete años después, el 1 de enero de 2008, el INE certificaba que los rumanos estaban empadronados en 5.049, el 62,2\% de los 8.112 municipios españoles, una proporción superior a la de otros colectivos (cuadro 1). El proceso de difusión, extraordinario por su extensión y rapidez, se debe a la movilidad geográfica interna de la población rumana.

\section{LOS FLUJOS CON EL EXTERIOR. MADRID, PRINCIPAL PUERTA DE ENTRADA}

El principal objetivo de cualquier inmigrante es conseguir alojamiento, trabajo y (cuando no se tienen) los indispensables papeles. Diversos trabajos de investigación (Pajares, 2007; Castro, 2008; Grigoras, 2009) revelan las condiciones de hacinamiento en las viviendas ocupadas por rumanos en los primeros 
momentos de la migración. Esto es así porque al recién llegado, con escasos recursos, sin trabajo o con empleos ocasionales y, en muchos casos, sin permiso de residencia, le resulta prácticamente imposible alquilar un piso. En estas circunstancias, es habitual que en las primeras semanas o meses de estancia comparta vivienda, y a veces habitación, con otras personas, la mayoría familiares y amigos, que le acogen de forma gratuita o subarriendan una habitación con el fin de compartir gastos. La red social es también la principal vía para encontrar el primer empleo. Así se explica que las provincias que cuentan con más residentes rumanos (figura 2) sean las que registran un mayor número de entradas (cuadro 2).

Entre 2001 y 2007, el INE contabilizó 667.636 inmigraciones de ciudadanos rumanos en España, más de 95.000 al año por término medio, con un notable incremento en 2007. La mayor parte ha entrado por la Comunidad de Madrid, que ocupa un destacado primer puesto, a mucha distancia de varias provincias mediterráneas y otras próximas a la capital, además de Zaragoza. El hecho más re-

Cuadro 2. Flujos de entrada y salida de la población rumana residente en España entre 2001 y 2007 (\%)

\begin{tabular}{|c|c|c|c|c|c|c|c|c|}
\hline & 2001 & 2002 & 2003 & 2004 & 2005 & 2006 & 2007 & 2001-07 \\
\hline $\begin{array}{l}\text { Inmigraciones } \\
\text { (número) }\end{array}$ & 23.295 & 48.330 & 55.046 & 103.572 & 108.294 & 131.457 & 197.642 & 667.636 \\
\hline Madrid & 44,80 & 40,80 & 35,68 & 27,33 & 23,72 & 29,16 & 20,64 & 27,4 \\
\hline Valencia & 6,54 & 6,02 & 6,43 & 5,50 & 5,84 & 5,99 & 6,46 & 6,1 \\
\hline Zaragoza & 4,33 & 3,16 & 3,21 & 5,58 & 5,63 & 5,06 & 5,86 & 5,2 \\
\hline Castellón & 5,55 & 7,70 & 10,88 & 7,00 & 6,10 & 7,16 & 4,77 & 6,5 \\
\hline Barcelona & 3,12 & 2,82 & 2,48 & 4,83 & 4,68 & 4,19 & 4,44 & 4,2 \\
\hline Alicante & 3,89 & 3,99 & 4,37 & 3,80 & 3,91 & 3,89 & 3,85 & 3,9 \\
\hline Toledo & 4,03 & 3,66 & 2,99 & 3,90 & 4,07 & 4,43 & 3,74 & 3,9 \\
\hline Tarragona & 2,50 & 2,65 & 2,13 & 3,71 & 3,51 & 3,52 & 3,44 & 3,3 \\
\hline Ciudad Real & 2,45 & 3,18 & 3,22 & 2,95 & 3,55 & 2,92 & 3,39 & 3,2 \\
\hline Almería & 4,64 & 3,31 & 3,46 & 4,59 & 4,98 & 2,93 & 2,82 & 3,6 \\
\hline Lérida & 1,67 & 1,84 & 1,83 & 2,78 & 2,63 & 2,34 & 2,58 & 2,4 \\
\hline Huelva & 0,15 & 0,42 & 0,53 & 1,21 & 2,08 & 1,21 & 2,53 & 1,6 \\
\hline Las 12 & 83,67 & 79,55 & 77,20 & 73,18 & 70,72 & 72,80 & 64,52 & 71,3 \\
\hline $\begin{array}{l}\text { Emigraciones } \\
\text { (número) }\end{array}$ & $\mathrm{Sd}^{*}$ & 234 & 632 & 3.148 & 4.044 & 16.446 & 8.050 & 32.554 \\
\hline
\end{tabular}

Fuente: INE, Estadística de Variaciones Residenciales [www.ine.es]. Elaboración propia.

Se indican las provincias que en 2007 superaban el $2 \%$ de las inmigraciones.

* Los datos de emigración al extranjero empiezan a publicarse en 2002. 
levante es que hace apenas cinco o seis años, Madrid llegó a concentrar más del $40 \%$ de las entradas, frente a poco más del $20 \%$ en el momento actual. Esta pérdida de protagonismo revela la rápida y progresiva ampliación del espacio migratorio, que ha incorporado otras provincias y ciudades como puntos de llegada. El proceso se relaciona con la movilidad geográfica interna de los inmigrantes, que cambian de provincia de residencia buscando mejores oportunidades laborales y de vivienda, de manera que muchos de los que han venido a España en fecha reciente acuden directamente a los nuevos lugares de destino, donde ya cuentan con contactos.

En el mismo periodo de siete años, constan 32.554 emigraciones, la mitad de ellas en $2006^{5}$. Las provincias de salida coinciden, en líneas generales, con las de entrada, con Madrid a la cabeza (23,5\%), aunque el orden se modifica, destacando en el sexto puesto (con menos del 4\%) la provincia de Vizcaya.

\section{ESTRUCTURA TERRITORIAL DE LA MOVILIDAD INTERIOR}

La movilidad interna de la población rumana ha experimentado un aumento espectacular en cifras absolutas: en 2001 se registraron 5.266 cambios de municipio de residencia y en 2007 se han superado los 70.000. El mayor incremento se da en 2005, el año del proceso de «normalización de trabajadores extranjeros», y en 2007, el del ingreso de Rumania en la UE, y en un contexto de aumento generalizado de los desplazamientos protagonizados por extranjeros (cuadro 3). La movilidad registra mayor intensidad entre los rumanos, que en 2007 multiplicaron por trece el número de desplazamientos con respecto a los de 2001 (figura 3), en tanto que los búlgaros lo han hecho por diez, los marroquíes por cinco, al igual que el conjunto de la población extranjera, mientras que la cifra apenas se ha modificado en el caso de los españoles. Las tasas de migración de los rumanos son en todo momento superiores a las del resto de extranjeros ${ }^{6}$. Sin embargo, mientras los índices de éstos han seguido aumentado, aunque lo hayan hecho de forma modesta, los valores relativos del colectivo rumano disminuyen, con lo que las diferencias entre unos y otros se reducen.

${ }^{5}$ En 2006, el INE dio de baja a 9.516 ciudadanos rumanos que no acudieron a los ayuntamientos a renovar la inscripción en el Padrón, con lo que la emigración real sería mayor que la indicada en el cuadro 2. En abril de 2005, el INE dictó instrucciones a los ayuntamientos para la aplicación de la Ley 7/1985 Reguladora de las Bases del Régimen Local, que establece la renovación periódica cada dos años de las inscripciones en el Padrón de los extranjeros no comunitarios sin autorización de residencia permanente y la caducidad de dichas inscripciones en caso de no llevarse a cabo tal renovación.

${ }^{6}$ Los marroquíes se mueven más en términos absolutos y relativos, con un total de 85.838 movimientos en 2007 y una tasa de 139 por mil. 
Cuadro 3. Cambios de municipio de residencia en España (2001-2007)

\begin{tabular}{|c|c|c|c|c|c|c|}
\hline & \multicolumn{2}{|c|}{ Rumanos } & \multicolumn{2}{c|}{ Extranjeros* $^{*}$} & \multicolumn{2}{c|}{ Españoles } \\
\hline Año & Movimientos & Tasa & Movimientos & Tasa & Movimientos & Tasa \\
\hline 2001 & 5.266 & 106,47 & 99.535 & 61,26 & 889.814 & 22,35 \\
\hline 2002 & 15.000 & 146,61 & 223.866 & 100,90 & 1.085 .061 & 27,16 \\
\hline 2003 & 21.468 & 124,34 & 272.122 & 101,67 & 1.174 .313 & 29,28 \\
\hline 2004 & 28.629 & 108,99 & 329.109 & 105,49 & 1.169 .708 & 29,05 \\
\hline 2005 & 39.168 & 108,12 & 362.709 & 101,45 & 1.168 .484 & 28,87 \\
\hline 2006 & 50.093 & 107,24 & 412.885 & 106,83 & 1.269 .331 & 31,25 \\
\hline 2007 & 70.135 & 111,43 & 465.058 & 109,05 & 1.260 .160 & 30,90 \\
\hline
\end{tabular}

Fuente: INE, Estadística de Variaciones Residenciales [www.ine.es]. Elaboración propia.

* No se incluyen los de nacionalidad rumana.

La tasa de movilidad expresa el número de cambios de municipio de residencia por cada mil efectivos de cada colectivo.

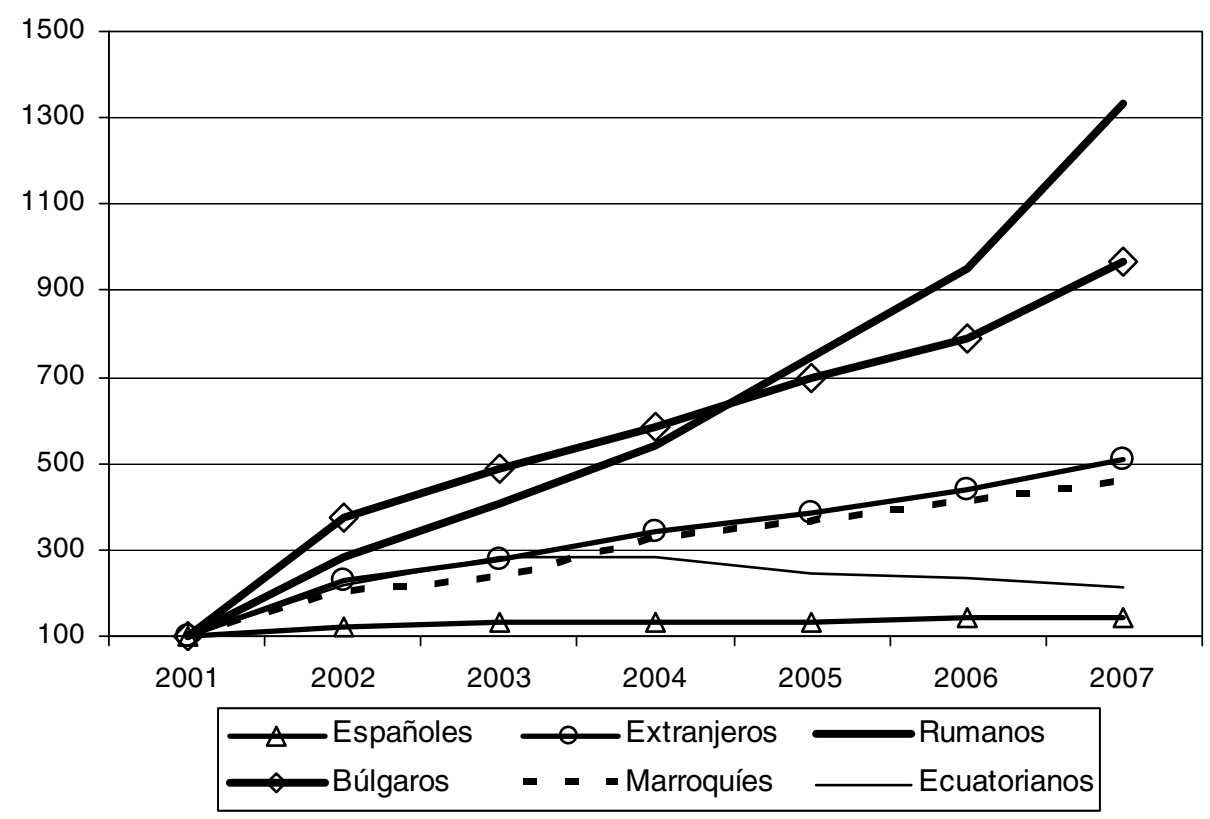

Fuente: INE, Estadística de Variaciones Residenciales [www.ine.es].

Figura 3. Evolución indexada de las migraciones interiores $(2001=100)$. 
Es evidente que para muchos de los rumanos que residen en España, el primer destino no es el definitivo y, al cabo de un tiempo, cambian de lugar de residencia con el fin de mejorar las improvisadas condiciones iniciales, al igual que hacen otros grupos de extranjeros (García, 2005; Pumares, García y Asensio, 2006). En términos relativos, la movilidad interna era extremadamente elevada en los primeros años (cuadro 3), en la fase de adaptación a un nuevo contexto espacial. La posterior reducción de las tasas debe relacionarse con la estabilidad laboral de buena parte del colectivo y con el reagrupamiento familiar, mientras que el aumento registrado en 2007 se debe al notable incremento de efectivos el mismo año del ingreso de Rumania en la UE.

\section{Predominio de los desplazamientos a corta distancia}

La movilidad de los rumanos es más importante en los desplazamientos intraprovinciales, que suponen el $57 \%$ de los 229.759 cambios de residencia contabilizados entre 2001 y 2007 (cuadro 4). Los desplazamientos de corto recorrido se incrementarían si, a los que se producen dentro de la misma provincia, añadimos los que tienen lugar entre provincias vecinas, que suman 37.283, el $16,2 \%$ del total. Así pues, la proximidad es un elemento clave en las migraciones interiores y adquiere más importancia en las grandes áreas metropolitanas y en las provincias con mayor número de residentes, como ocurre en Castellón (véase el apéndice). Sólo Madrid registra el 36,4\% de la movilidad intraprovincial y el intercambio de migrantes que mantiene con provincias aledañas es el de ma-

Cuadro 4. Tipo de migración interior de los ciudadanos rumanos

\begin{tabular}{|c|r|c|c|c|c|c|c|c|r|}
\hline \multirow{2}{*}{ Añ o } & \multirow{2}{*}{ Intraprovincial } & \multicolumn{6}{|c|}{ Interprovincial, según las provincias } & \\
\cline { 5 - 11 } & & \multicolumn{2}{|c|}{ Vecinas } & \multicolumn{2}{|c|}{ Otras } & \multicolumn{2}{|c|}{ Total } & TOTAL \\
\hline & Número & $\%$ & Número & $\%$ & Número & $\%$ & Número & $\%$ & Número \\
\hline 2001 & 2.714 & 51,5 & 911 & 17,3 & 1.641 & 31,2 & 2.552 & 48,5 & 5.266 \\
\hline 2002 & 8.814 & 58,8 & 2.301 & 15,3 & 3.885 & 25,9 & 6.186 & 41,2 & 15.000 \\
\hline 2003 & 12.613 & 58,8 & 3.420 & 15,9 & 5.435 & 25,3 & 8.855 & 41,2 & 21.468 \\
\hline 2004 & 16.555 & 57,8 & 4.448 & 15,5 & 7.626 & 26,6 & 12.074 & 42,2 & 28.629 \\
\hline 2005 & 23.071 & 58,9 & 6.304 & 16,1 & 9.793 & 25,0 & 16.097 & 41,1 & 39.168 \\
\hline 2006 & 30.394 & 60,7 & 7.873 & 15,7 & 11.826 & 23,6 & 19.699 & 39,3 & 50.093 \\
\hline 2007 & 36.843 & 52,5 & 12.026 & 17,1 & 21.266 & 30,3 & 33.292 & 47,5 & 70.135 \\
\hline $2001-2007$ & 131.004 & 57,0 & 37.283 & 16,2 & 61.472 & 26,8 & 98.755 & 43,0 & 229.759 \\
\hline
\end{tabular}

Fuente: INE, Estadística de Variaciones Residenciales [www.ine.es]. Elaboración propia. 
yor volumen de los desplazamientos que tienen lugar entre provincias vecinas. Es aquí donde la vecindad alcanza mayor importancia como porcentaje de la migración interprovincial (véanse las dos columnas de la derecha en el apéndice). En cambio, la cercanía pierde peso en provincias con pocos efectivos y en una posición periférica, como ocurre en el norte, en Andalucía y en varias de Castilla y León.

Los movimientos migratorios a corta distancia están relacionados fundamentalmente con el mercado de la vivienda ((Recaño, 2004; García, 2005, Pumares, García y Asensio, 2006). Las investigaciones empíricas destacan el carácter provisional del primer alojamiento. Los rumanos cambian de domicilio por motivos diversos: problemas de convivencia con otros inquilinos, búsqueda de privacidad y de un alojamiento más confortable cuando mejoran las condiciones laborales, reagrupamiento familiar, etc. En las grandes áreas metropolitanas, el cambio de residencia supone con frecuencia el traslado a otra localidad donde los precios de la vivienda resultan más asequibles y también por motivos laborales, como apuntan estudios recientes (Grigoras, 2009). Algunos inmigrantes, sobre todo los de etnia gitana (Macías, 2007; Pajares, 2007), se han visto presionados a cambiar de municipio de residencia.

No obstante el predominio de los desplazamientos de proximidad sobre los de media y larga distancia, estos últimos (descartados los que tienen lugar entre provincias vecinas) experimentan un notable incremento en 2007 , representando el 30\% del total. Las migraciones interprovinciales revelan de forma clara las diferentes oportunidades que encuentran los extranjeros entre unas provincias y otras.

\section{Migración interprovincial: provincias emisoras y provincias receptoras}

Los cerca de 99.000 desplazamientos interprovinciales registrados entre 2001 y 2007 arrojan un balance de 25 provincias con saldo positivo y otras 25 con saldo negativo (figura 4). Para analizar los cambios que en un tema como éste llegan a producirse en muy poco tiempo, se compara lo ocurrido en los cinco primeros años (figura 5) con el balance de los dos últimos (figura 6) ${ }^{7}$. La mayor parte de las provincias han continuado con el mismo signo migratorio, registrándose cambios relevantes en algunos casos, por ejemplo, en Castellón y Zaragoza, dos de las provincias con mayor número de residentes rumanos, donde el balance negativo de los primeros años se torna positivo en fecha reciente.

En general, las provincias con más efectivos registran un mayor volumen de salidas y entradas y los mayores saldos. Sin embargo, el componente demográfico no puede explicar por sí solo la dinámica migratoria, ya que provincias con un

${ }^{7}$ Aunque el número de desplazamientos interprovinciales es ligeramente superior en 20062007, el 54\% del total, la escala de la leyenda es la misma en los mapas de las figuras 5 y 6 para facilitar la comparación.

EMPIRIA. Revista de Metodología de Ciencias Sociales. N. . 19, enero-junio, 2010, pp. 157-181. ISSN: $1139-5737$ 


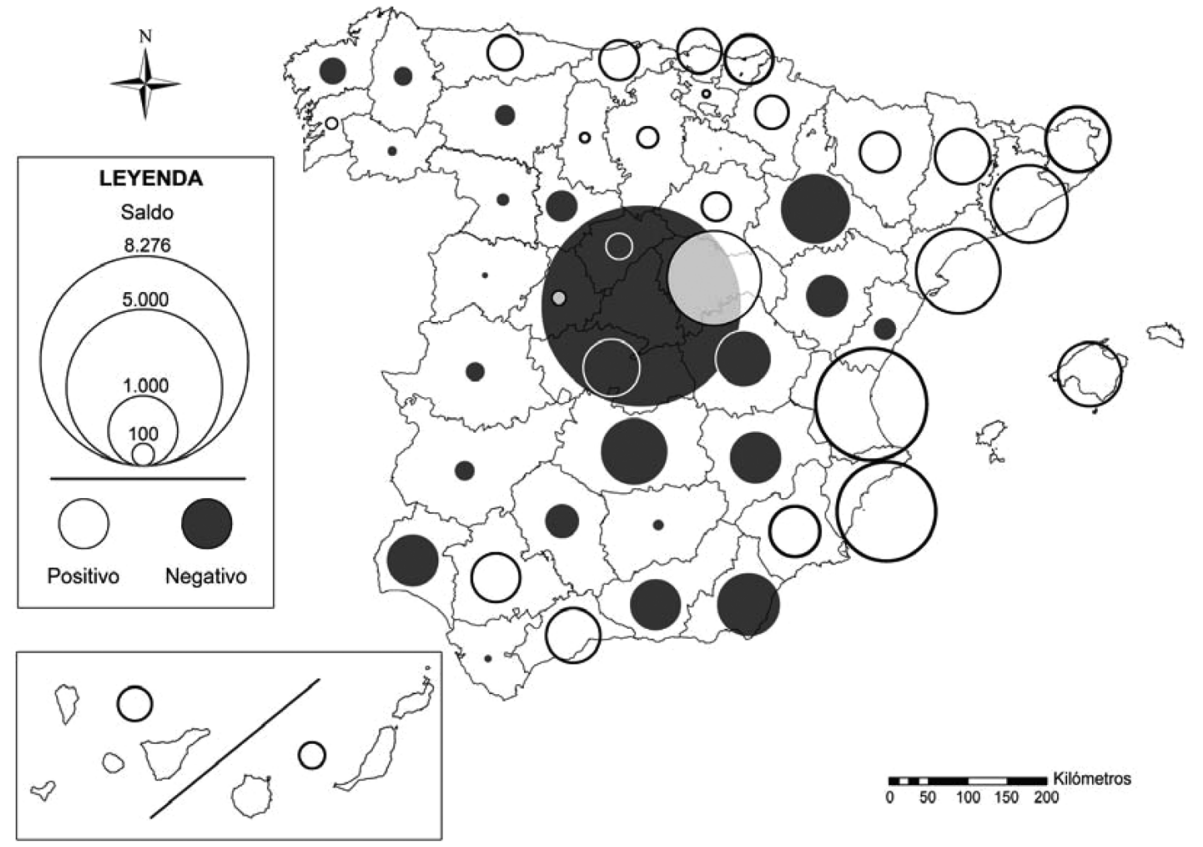

Fuente: INE, Estadística de Variaciones Residenciales [www.ine.es].

Figura 4. Saldo migratorio interprovincial de la población rumana (2001-2007).

gran número de residentes rumanos o con similar proporción desempeñan papeles distintos. Como han señalado otros autores (Pumares, García y Asensio, 2006), también hay que considerar aspectos relacionados con el mercado de trabajo y la vivienda, e incluso otros menos tangibles, como la actitud de la sociedad y de las autoridades locales hacia la población extranjera (Potot, 2007; Macías, 2007).

Los saldos absolutos de mayor tamaño dibujan dos espacios de comportamiento muy diferente. El litoral mediterráneo constituye el foco más atractivo para los rumanos procedentes de otras provincias, en relación con su dinamismo económico y la oferta de empleo amplia y diversificada: construcción, agricultura intensiva de regadío, servicio doméstico, industria, actividades relacionadas con el turismo, etc. Este eje abarca de Gerona a Murcia, incluyendo Baleares, y se ha completado en fecha reciente con el cambio de tendencia registrado en Castellón. La España más atractiva se completa con Guadalajara, que se afianza como una de las provincias con mayores ganancias (figuras 5 y 6 ), lo que se debe fundamentalmente a la expansión urbana desde Madrid. También son receptoras netas las provincias andaluzas de Sevilla y Málaga, las del valle del Ebro, donde destaca el cambio de signo de Zaragoza y la Rioja, el País Vasco, Cantabria y Asturias. Los saldos son modestos pero van en aumento, configu- 


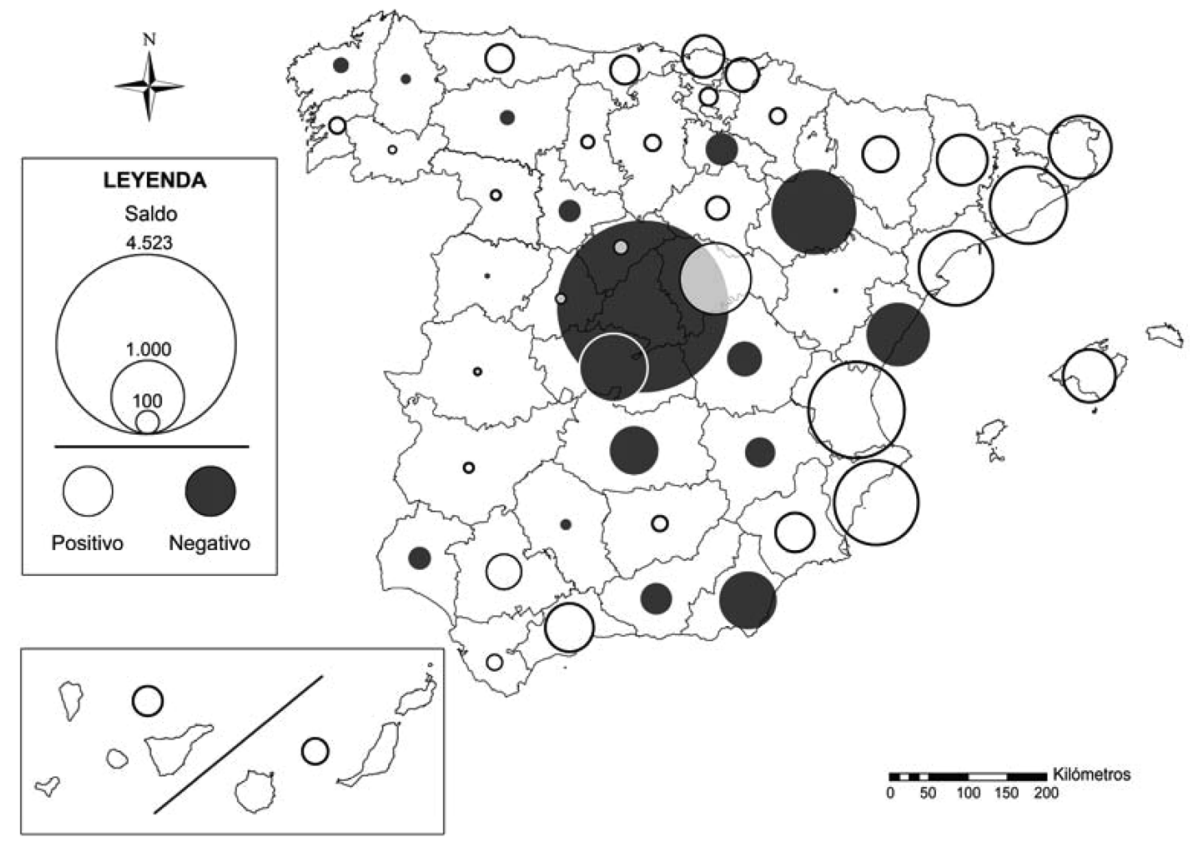

Fuente: INE, Estadística de Variaciones Residenciales [www.ine.es].

Figura 5. Saldo migratorio interprovincial de la población rumana (2001-2005).

rando una nueva área de atracción en el norte peninsular, aunque a un segundo nivel en comparación con el litoral mediterráneo. El balance entre las entradas y las salidas explica en buena medida el número de ciudadanos rumanos que reside en estas provincias, al igual que en Guadalajara, como indica el elevado saldo relativo (apéndice). En cambio, las del Mediterráneo incrementan el censo con inmigrantes que llegan directamente del exterior y desde otras provincias españolas, demostrando una gran capacidad de retención.

Madrid es el primer destino para muchos de los inmigrantes que llegan a España y se responsabiliza de buena parte de las relocalizaciones residenciales que protagoniza este colectivo. Es la provincia que pierde más efectivos por migración interna. El volumen de su saldo negativo es similar a la suma de las ganancias netas en cinco provincias mediterráneas (Valencia, Alicante, Tarragona, Barcelona y Gerona). No obstante, este balance no significa que Madrid tenga una gran capacidad de expulsión, pues la variación relativa (con un saldo del $10 \%$ ) es una de las más bajas entre las provincias españolas, lo que significa que retiene la mayor parte de la población que recibe. El saldo absoluto madrileño es consecuencia directa del elevado número de residentes y de las continuas entradas y salidas de ciudadanos rumanos. 


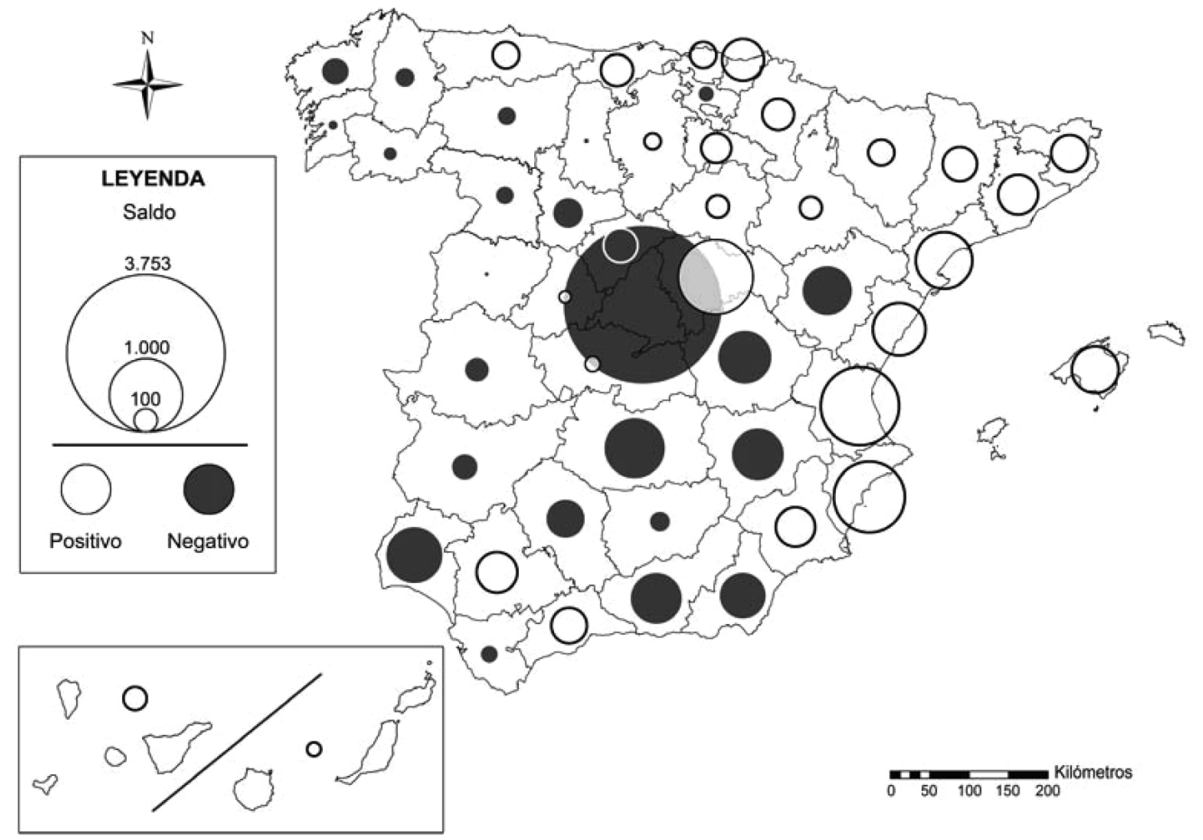

Fuente: INE, Estadística de Variaciones Residenciales [www.ine.es].

Figura 6. Saldo migratorio interprovincial de la población rumana (2006-2007).

Castilla-La Mancha (salvo Guadalajara), Almería, Huelva y Granada, Teruel y Zaragoza han expulsado a un gran número de rumanos durante el periodo 2001-2007 (figura 4). Excepto Zaragoza, cuyo saldo se ha modificado por la llegada de un gran número de trabajadores atraídos por la oferta de empleo que ha generado la Expo 2008, las otras provincias han ido acumulando pérdidas año tras año ${ }^{8}$ (figuras 5 y 6 ). Se nutren básicamente de inmigrantes que proceden de otras regiones porque los problemas relacionados con el trabajo, la vivienda o la situación administrativa encuentran aquí más rápida solución. La búsqueda de papeles es uno de los factores que explica el reciente y súbito aumento de la inmigración en Castilla-La Mancha (EAPN, 2006). Muchos rumanos consiguen aquí la primera oportunidad para trabajar gracias a la amplia oferta de empleo agrario. La irregularidad administrativa no ha sido un obstáculo porque los extranjeros son necesarios para el funcionamiento del sector y las autoridades se muestran tolerantes (Potot, 2000).

${ }^{8}$ El modesto saldo positivo de Toledo en 2006-2007 (figura 6) se debe al notable incremento de las altas durante el primer año. En 2007, las salidas han vuelto a superar a las entradas.

EMPIRIA. Revista de Metodología de Ciencias Sociales. N. ${ }^{19}$, enero-junio, 2010, pp. 157-181. ISSN: 1139-5737 
Sin embargo, buena parte de los que llegan a estas provincias se vuelven a ir porque las posibilidades de mejora sociolaboral son muy limitadas, lo que las convierte en lugares de paso (Muñoz y Herreros, 2004). Las entradas y salidas, importantes en valores absolutos y relativos, evidencian la elevada rotación que se registra en estas provincias, de manera que los empleos que abandonan los que salen son ocupados por los que llegan, cuando no se trata de individuos que van y vienen. Sea como fuere, el balance es negativo y los saldos más abultados se dan en las provincias castellanas y en Almería, cuya capacidad de expulsión es en términos relativos (con un saldo del 10\%) inferior a la de la mayor parte de las provincias españolas (véase el apéndice), sin duda por las oportunidades de trasvase sectorial que los rumanos encuentran en la misma provincia, ya sea en los servicios o en la construcción. El grado de expulsión registra mayor intensidad en Huelva $(33,6 \% \text { de saldo })^{9}$, donde se observa un notable descenso en la contratación de rumanos para tareas agrícolas de temporada (Gordo, 2008).

Finalmente, hay que referirse al gran número de provincias, alrededor de la mitad, que cuentan con pocos efectivos de nacionalidad rumana y que generan un volumen reducido de entradas y salidas. No obstante, cualquier movimiento se nota mucho en términos relativos. En este grupo se incluyen las provincias de Castilla y León, Galicia y Extremadura, con balance negativo en la mayoría de los casos. Son provincias a las que llegan migrantes desde otras regiones que, tras comprobar las escasas posibilidades de mejora sociolaboral, buscan nuevos espacios o regresan a las provincias de las que salieron.

\section{La dirección de los flujos entre provincias: el protagonismo de Madrid y el litoral mediterráneo}

La información disponible en los ficheros de microdatos permite un análisis individual de los desplazamientos. Para ello se han confeccionados dos mapas (figuras 7 y 8) que representan la dirección de los flujos de mayor volumen, los que superan los 300 movimientos entre 2001 y 2007, que equivalen al $43 \%$ de las migraciones interprovinciales, y otros dos mapas (figura 9) en los que se indica cuál es la principal provincia de origen y de destino de los rumanos. Los resultados obtenidos ponen de relieve que Madrid y el litoral valenciano y catalán marcan las pautas en la redistribución de la población rumana que reside en España. Madrid, Valencia, Castellón y Alicante son las provincias que aparecen con más frecuencia como origen o como destino en los flujos que superan los 500 movimientos, salvo en tres: los que salen de Barcelona hacia Gerona y Tarragona, y el que va de Toledo a Ciudad Real (figura 8).

${ }^{9}$ En realidad, le supera Lugo. Pero el valor de la provincia gallega es irrelevante ya que cuenta con pocos residentes de esta nacionalidad. 


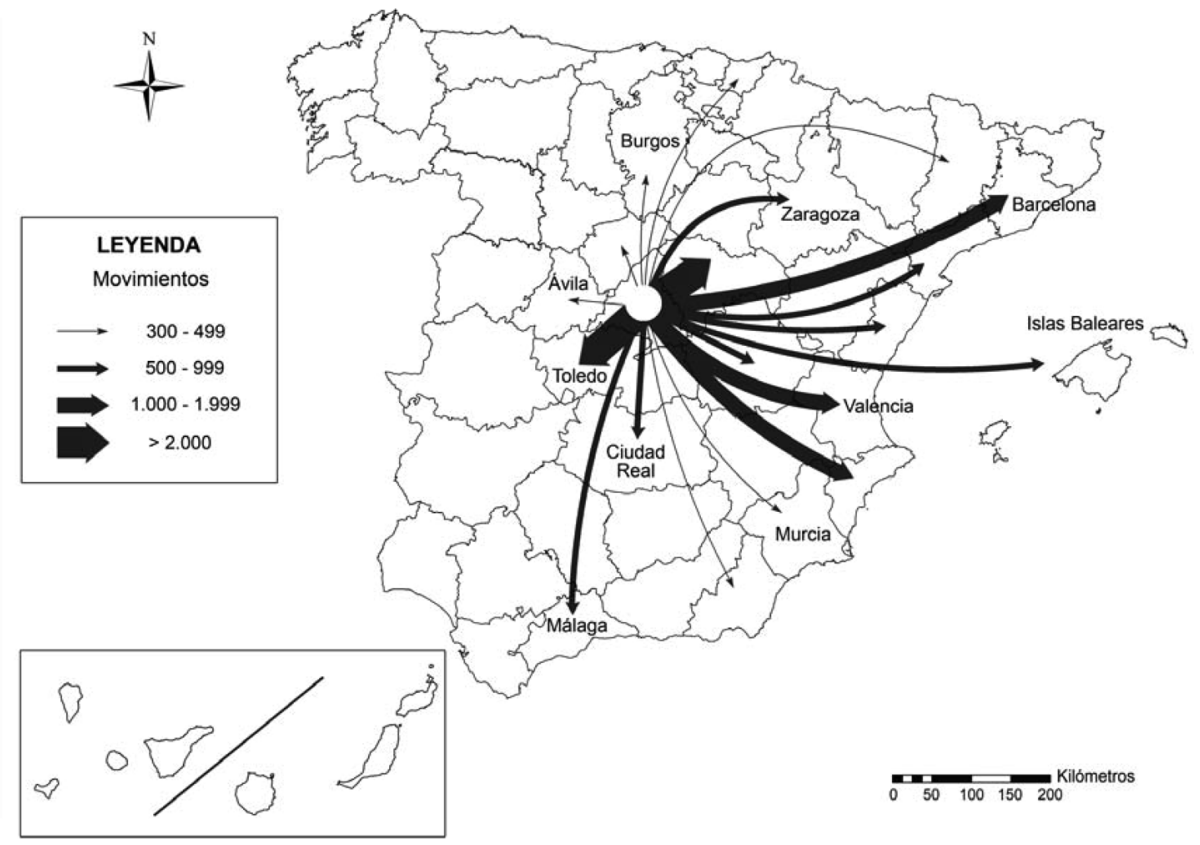

Fuente: INE, Estadística de Variaciones Residenciales [www.ine.es].

Figura 7. Principales flujos interprovinciales de los rumanos que salen de Madrid (2001-2007).

El protagonismo de Madrid se pone de manifiesto en las cifras absolutas. Con cerca del $22 \%$ de las bajas padronales, es el principal centro difusor de migrantes hacia otras provincias, a mucha distancia de Zaragoza, Valencia, Toledo y Castellón, que suman el 23\% de las salidas. Madrid es, además, el principal centro receptor (13,3\% de las altas), seguido por la Comunidad Valenciana y Toledo, que reúnen el 24\% de la inmigración interprovincial. Por otra parte, Madrid cuenta con una extensa zona de influencia: es el principal destino para los rumanos que salen de 24 provincias y ocupa el primer puesto como origen de los rumanos que llegan a 33 provincias (figura 9). No obstante, en la mayoría de los casos, estos desplazamientos generan pocos movimientos ya que no aparecen representados en el mapa de flujos (figuras 7 y 8). El peso de Madrid se deja sentir sobre todo en las provincias aledañas pues la inmensa mayoría de los rumanos que entran o salen de ellas pasan por allí. El caso más llamativo es el de Guadalajara, no sólo por el volumen de movimientos, sino también porque el flujo que llega desde Madrid supera la movilidad que se produce dentro de la provincia castellana ${ }^{10}$.

${ }^{10}$ Lo mismo se puede decir de Soria y de Segovia, pero en estos casos el número de desplazamientos es muy bajo. 


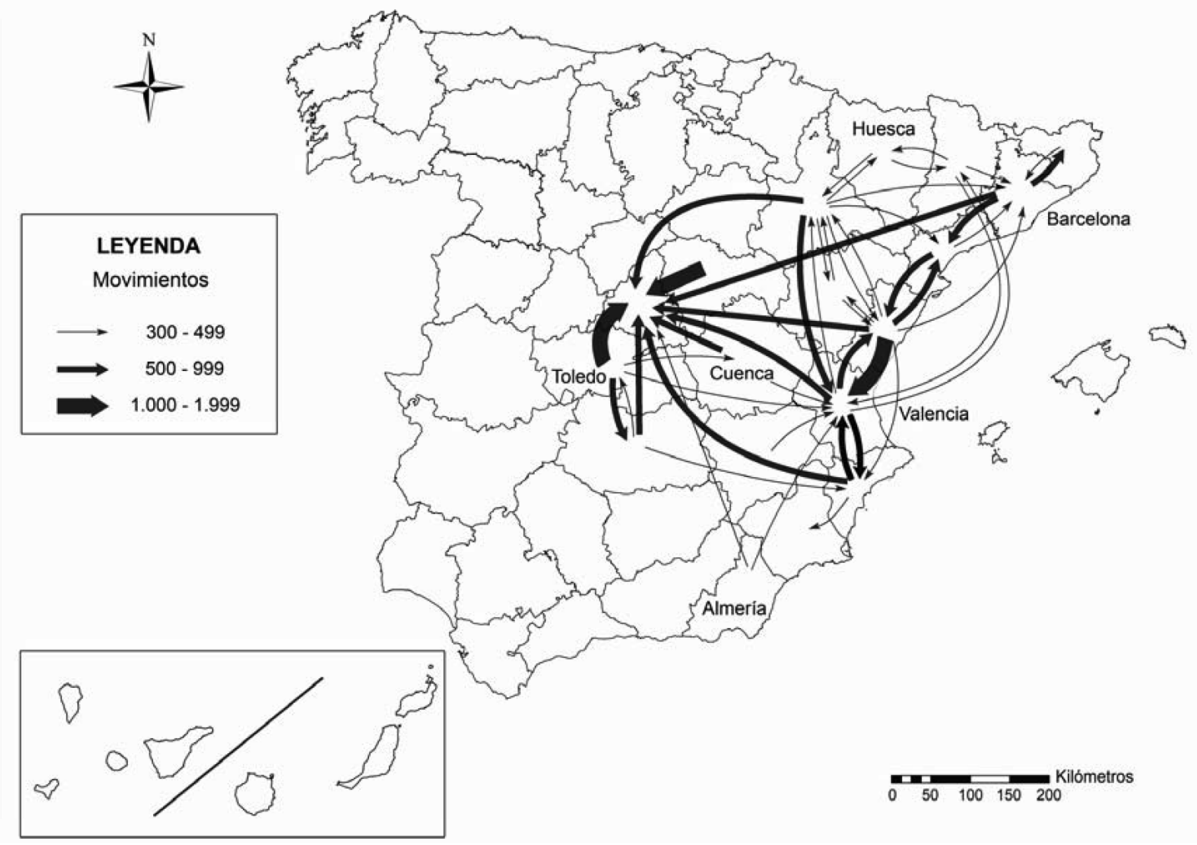

Fuente: INE, Estadística de Variaciones Residenciales [www.ine.es].

Figura 8. Principales flujos interprovinciales de los rumanos, excepto los que salen de Madrid (2001-2007).
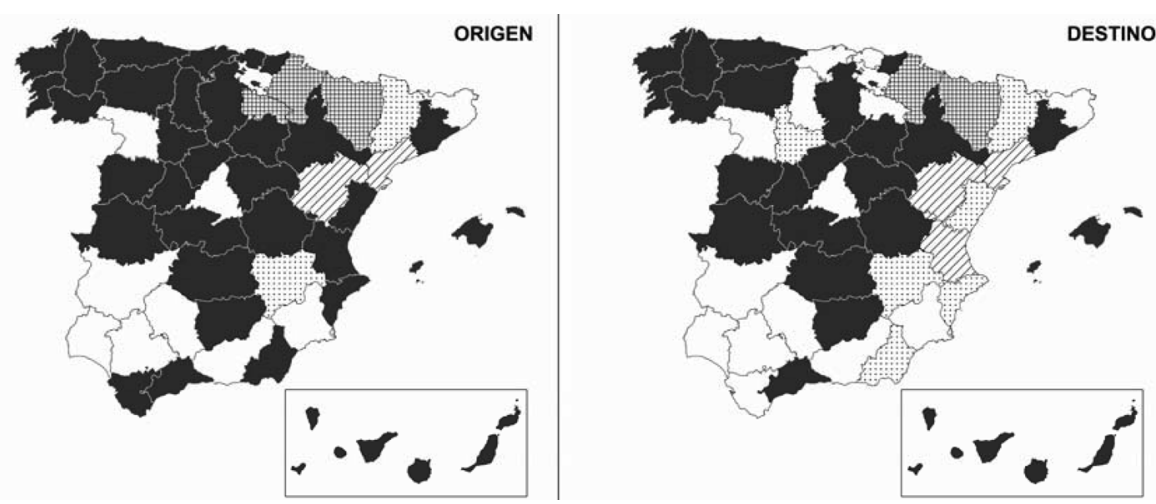

Fuente: INE, Estadística de Variaciones Residenciales [www.ine.es].

Figura 9. Principales provincias de origen y destino de la migración interprovincial de los rumanos (2001-2007). 
Como se puede apreciar en la figura 9, la hegemonía de Madrid como centro emisor o receptor de migrantes se disipa en algunos sectores del territorio. Así, en Andalucía occidental y Badajoz cada provincia tiene a su vecina como principal punto de entrada o salida de inmigrantes rumanos. Zaragoza organiza buena parte de los desplazamientos que se producen en el valle del Ebro. Valencia y Castellón hacen lo propio en el litoral mediterráneo, sobre todo como provincias de acogida. Valencia mantiene un intercambio relativamente importante de migrantes con Lérida y es la principal provincia de destino para los rumanos que salen de Valladolid.

En definitiva, la dirección de los flujos interprovinciales dibuja una red principal de intercambios entre Madrid y provincias del entorno (el $10 \%$ de la movilidad interprovincial tiene lugar entre Madrid, Toledo y Guadalajara) y entre Madrid y el litoral mediterráneo (otro 10\%, aproximadamente). A esta red principal se añade un segundo espacio de movimientos significativos entre provincias mediterráneas, alrededor del $7 \%$, que completa un gran triángulo de movilidad con vértices en Madrid, Barcelona y Alicante. Finalmente, se observan intercambios reseñables entre las provincias mediterráneas y las del valle del Ebro o la Mancha, con predominio de los flujos que se dirigen hacia la costa.

\section{A MODO DE CONCLUSIÓN: LA MOVILIDAD GEOGRÁFICA COMO ESTRATEGIA PARA MEJORAR LAS CONDICIONES DE VIDA}

Los resultados obtenidos del análisis de la EVR coinciden con las investigaciones empíricas al destacar la elevada movilidad de la población rumana. El $38 \%$ de los ciudadanos rumanos encuestados en septiembre de 2008 en la provincia de Madrid ha cambiado de municipio de residencia (Grigoras, 2009). Según la estadística, la movilidad interna de los rumanos es muy superior a la de los españoles y una de las más altas entre la población extranjera, lo que se debe al rápido incremento del stock de residentes y a que se trata de un flujo muy reciente. Entre las nacionalidades con mayor número de efectivos, sólo la marroquí tiene un índice más alto. A diferencia de los norteafricanos, la movilidad de los rumanos es más importante en los desplazamientos intraprovinciales que, junto con los que tienen lugar entre provincias vecinas, suponen cerca del $75 \%$ de los movimientos registrados en los últimos siete años. La proximidad es, en efecto, uno de los rasgos más destacables en las migraciones interiores de este colectivo.

El balance territorial de los desplazamientos a media y larga distancia es muy desigual y coincide en lo fundamental con las observaciones de otros autores (Pumares, Garcia y Asensio, 2006). Madrid es el principal centro receptor-redistribuidor de migrantes. Castilla-Mancha y varias provincias andaluzas, con una importante oferta de empleo en el sector agrario, actúan como espacio de 
acogida en una primera fase del proceso migratorio y trampolín desde donde se desplazan a regiones más dinámicas del litoral mediterráneo, con mayor capacidad para retener la población gracias a la amplia y diversificada oferta de empleo. Guadalajara es la gran excepción en el interior por su balance positivo, efecto de la emigración desde Madrid relacionada con su expansión urbana y económica. Otras regiones, con menor tradición en la recepción de extranjeros, el valle del Ebro, el País Vasco y el litoral cantábrico, se han convertido en nuevos espacios de acogida de rumanos por migración interna. Finalmente, hay lugares que, según las circunstancias del mercado de trabajo, pasan de ser difusores a receptores de migrantes, como Castellón o Zaragoza. En ambos casos, el cambio de tendencia se relaciona, entre otros factores, con la oferta de empleo en el sector de la construcción, que antes de la crisis ocupaba a más de la mitad de los trabajadores de nacionalidad rumana (Domingo, Gil y Maisongrande, 2008). En las actuales circunstancias económico-laborales es probable que en 2008 hayan vuelto a registrar más bajas que altas padronales.

Como en el caso de los marroquíes (Pumares, 2005), el cambio de municipio de residencia favorece la dispersión y modifica continuamente la distribución geográfica. A este respecto, interesa señalar que Madrid llegó a concentrar más del $40 \%$ de los rumanos residentes en España a principios del siglo XXI y en la actualidad apenas cuenta con el 26\% (Viruela, 2008). El proceso de difusión ha sido de tal magnitud que los inmigrantes de nacionalidad rumana han logrado la mayor expansión territorial (están presentes en más de 5.000 municipios españoles), superando a los marroquíes que llevan muchos más años de experiencia migratoria en nuestro país.

La EVR no proporciona información de los motivos del desplazamiento, que otras fuentes estadísticas, en especial la Encuesta Nacional de Inmigrantes, y los estudios cualitativos pueden desvelar. Los resultados de algunas investigaciones empíricas sobre el colectivo rumano en España (muy pocas, de momento) y varios estudios sobre la inmigración en diferentes regiones indican que la movilidad geográfica se debe, entre otros factores, a cuestiones relacionadas con el mercado laboral y de la vivienda, con las redes sociales o la actitud de la sociedad y de las autoridades locales hacia los extranjeros.

En los desplazamientos a corta distancia la vivienda es el principal factor de movilidad, sobre todo cuando el cambio de domicilio se produce en el seno de las áreas metropolitanas. En los primeros momentos, la mayor parte de los inmigrantes rumanos viven en condiciones de hacinamiento y, con el fin de reducir gastos, es habitual que varias personas compartan la misma habitación. Esta primera vivienda cumple la función de residencia de «tránsito» (Grigoras, 2009: 116), algo provisional, que se abandona a la primera oportunidad, cuando mejora la situación económico-laboral, se conoce el idioma, etc. En cambio, las migraciones interprovinciales y también buena parte de las intraprovinciales se deben a motivos laborales. Así, ante las dificultades para establecerse en Madrid, muchos rumanos se desplazan a Castilla y León (Delgado et al., 2006), Castilla-La Mancha (EAPN, 2006), Almería (Potot, 2007), etc., donde la incorporación al 
mercado de trabajo resulta más fácil. En general, aunque se encuentren en situación de irregularidad administrativa, son bien acogidos por los empresarios y por la sociedad porque es una mano de obra necesaria. Las autoridades, en connivencia con los empleadores, se muestran tolerantes e incluso les ayudan en el proceso de inserción, siendo éste un factor más que orienta a los inmigrantes hacia estas provincias y regiones ${ }^{11}$. En este sentido, como ya señaló hace años Swanie Potot (2000), la obtención del permiso de residencia ha contribuido a la movilidad interior, ya que cuando consiguen regularizar la situación se desplazan a otras provincias en busca de oportunidades más acordes con sus aspiraciones.

Con frecuencia, los desplazamientos a media o larga distancia van acompañados de movilidad laboral, con trasvase de la agricultura a los servicios, la industria o la construcción. Es el caso de miles de rumanos que han recalado en provincias del litoral o van a Madrid tras una etapa, más o menos larga, en provincias donde tuvieron la primera oportunidad. Otros cambian de domicilio para mantenerse activos durante más tiempo, aunque no cambien de sector, como hacen los trabajadores rumanos que se desplazan de unas provincias a otras siguiendo la «ruta de las recolecciones»: fruta en Lérida o Zaragoza, champiñón en la Rioja, vendimia en diferentes provincias de Castilla y León, que algunos completan con el trabajo en los almacenes donde se preparan las plantas de fresa, diferentes campañas agrarias en Castilla-La Mancha (ajo, cebolla, vendimia), Andalucía (aceituna, fresa), Valencia o Murcia (cítricos, productos de huerta), etc. Los acuerdos firmados entre asociaciones de agricultores de diferentes regiones permiten que miles de rumanos trabajen de forma continuada durante una larga temporada ${ }^{12}$. Los miembros de la minoría rom se desplazan por los mismos motivos que sus compatriotas y han encontrado en la movilidad agraria una vía de inserción laboral en el arco mediterráneo (Martínez Ibars, 2008). Pero, en ocasiones, se han visto forzados a cambiar de lugar de residencia por incidentes con los vecinos relacionados con la ocupación de viviendas, los asentamientos, etc., o por decisión de las autoridades locales ${ }^{13}$ (Macías, 2007; Pajares, 2007).

${ }^{11}$ Véase a este respecto Gago, Álvaro (2006): «Los inmigrantes utilizan la provincia como trampolín para trasladarse a otras ciudades», El Norte de Castilla, 11 de agosto de 2006.

${ }_{12}$ Ruano, Rebeca (2007): «Un vendimiador rumano gana en la Ribera el cuádruple que un directivo en su país», El Norte de Castilla, 28 de octubre de 2007. Estos acuerdos se realizan para la contratación de mano de obra en origen, que regula el Ministerio de Trabajo e Inmigración, que contempla la oferta para atender campañas concatenadas. Véase, por ejemplo, la resolución de 26 de diciembre de 2006 de la Secretaría de Estado de Inmigración y Emigración (BOE, núm. 8, de 9 de enero de 2007).

${ }^{13}$ El primer grupo numeroso de gitanos rumanos se asentó en Madrid a finales del siglo pasado, en el descampado de Malmea (Fuencarral), de donde fueron desalojados por la policía. Tras el desmantelamiento del poblado, parte del grupo se dirigió a otras provincias: Valencia, Barcelona, Vizcaya, etc. (Macías, 2007). La situación ha vuelto a repetirse en Barcelona y otros lugares, como ocurrió por ejemplo en la Herrera y otros municipios de la Mancha, a donde acudieron masivamente para trabajar en la vendimia de 2007. Véase, por ejemplo, Marina, Lorenzo (1999): «Manzano desaloja con excavadoras a los rumanos no censados en Malmea», El Mundo, 8 de septiembre de 1999; Gutiérrez, Vera (2000): «El alcalde declara que la etnia rumana no viene a Ma- 
Por otro lado, la movilidad geográfica funciona gracias a la red social que, en un grupo numeroso y de reciente inmigración como éste, se halla dispersa por el territorio. Cuando el número de efectivos aumenta de forma tan rápida como lo ha hecho el colectivo rumano, la saturación del mercado de trabajo en los principales lugares de destino produce un fuerte desequilibrio entre la oferta y la demanda de empleo local, las condiciones de vida de los extranjeros se degradan y disminuye el nivel de aceptación de la sociedad receptora ${ }^{14}$. En esos momentos, algunos buscan nuevos espacios alternativos de residencia, lo que abre posibilidades de migración circulatoria entre diferentes regiones y localidades. El inmigrante aprovecha las oportunidades de trabajo en distintos lugares para unirse a familiares y conocidos que residen aquí o allá en los momentos de mayor demanda (Maisongrande, 2008). Parte de estas migraciones están relacionadas con el trabajo agrario debido a la estacionalidad de las campañas, otros desplazamientos implican la alternancia de empleos en diferentes sectores de actividad.

\section{BIBLIOGRAFÍA}

ArANGO, J. (2004): «La inmigración en España a comienzos del siglo XXI». En Leal, Jesús (coord.), Informe sobre la situación demográfica en España, Madrid, Fundación Fernando Abril Martorell, pp. 161-186.

CASTRO, T. (2008): «Familias y hogares» en Rodríguez, Vicente (dir.): Inmigración, formación y empleo en la Comunidad de Madrid, Madrid, Consejo Económico y Social, Comunidad de Madrid, pp. 55-80.

CRISTESCU, J. y MunTELE, I. (2007): «Les conséquences humaines et territoriales du processus d'adhésion de la Roumanie a l'UE», L'Information Géographique, 7767: 121-141.

Delgado, J.M. -coord.- (2006): La nueva inmigración en Castilla y León, Valladolid, Consejo Económico y Social de Castilla y León, 539 p.

DIMINESCU, D. - dir.- (2003): Visibles mais peu nombreux. Les circulations migratoires roumaines, París, Éditions de la Maison des Sciences de l'Homme, 339 p.

Domingo, A.; Gil, F. y Maisongrande, V. (2008): «La inserción laboral de los inmigrantes rumanos y búlgaros en España», Cuadernos de Geografía, 84: 213-236.

Domingo, C. (2008): «Características demográficas de los migrantes búlgaros y rumanos en España», Cuadernos de Geografía, 84: 195-212.

EAPN (2006): Investigación de necesidades socio-laborales y propuestas para la integración de inmigrantes en Castilla-La Mancha, Toledo, Red Europea de Lucha contra la Pobreza y la Exclusión Social de Castilla-La Mancha, 178 p.

drid a trabajar, sino a situarse en la marginación», El País, 16 de mayo de 2000; Planelles, Manuel (2007): «La policía desaloja a 90 rumanos de un asentamiento en Córdoba», El País, 4 de septiembre de 2007; Andreu, Jerónimo (2007): «Los invisibles de la Herrera», El País, 10 de agosto de 2007.

${ }^{14}$ La llegada de un gran número de inmigrantes favorece la dispersión por saturación, como ocurrió por ejemplo hace años en Castellón: «una ciudad pequeña para que puedan vivir [y trabajar] tantos inmigrantes... cada día se nota más el rechazo al hecho de que se hable en lengua rumana» (Asociación de Países de Este. Véase, Viruela, 2002: 243). 
GARCíA, A. (2005): «Migraciones interiores y transformaciones territoriales», Papeles de Economía Española, 104: 76-91.

GoRdo, M. (2008): «La contratación en origen de rumanos para actividades agrícolas de temporada en España», Cuadernos de Geografía, 84: 237-262.

GrigorAs, V. (2009): «La habitación de los rumanos en España». En Sandu, Dumitru (coord.): Comunidades rumanas en España, Bucarest, Fundación Soros, pp. 110126. http://www.osf.ro/ro/program articol.php?articol=151\#

INE: Censo de Población y Viviendas 2001, http://www.ine.es

INE: Estadística de Variaciones Residenciales. Varios años, http://www.ine.es

INE: Padrón de Habitantes. Varios años, http://www.ine.es

MACÍAs, A. (2005): «La población romaní en el flujo migratorio del Este hacia Europa occidental: el caso de Rumania», Documentación Social, 137: 79-98.

- (2007): La emigración de la minoría étnica gitana de Rumania hacia España. Factores condicionantes de las migraciones internacionales. Tesis Doctoral, dirigida por Laparra, M. e Izquierdo, A., Departamento de Trabajo Social, Universidad Pública de Navarra (mimeo), 233 p. + anexos.

MAISONGRANDE, V. (2008): Les circulations migratoires roumaines en Europe: réseaux sociaux et inscription dans l' espace, Master II Migration Internationales, Espaces et Sociétés, Direction: Naik Miret, Université de Poitiers (mimeo), 161 p.

MARTí, M. y RóDENAS, C. (2006): «Reinterpretando el crecimiento de la movilidad en España: la población extranjera y las migraciones repetidas», Cuadernos Aragoneses de Economía, vol. 16, 1: 37-59.

MARTínez IbARs, R. (2008): La población rrom del Este Europeo en el Arco Mediterráneo. El largo camino hacia la inclusión social, Cartagena, Murcia, ASPROSOCU, $252 \mathrm{p}$.

MuÑoz, M. y Herreros, A. (2004): La inmigración en Castilla-La Mancha: una radiografía en 2003, Albacete, Altabán Ediciones y CCOO de Castilla-La Mancha, 234 p.

Pajares, M. (2007): Inmigrantes del Este. Procesos migratorios de los rumanos, Barcelona, Icaria, $274 \mathrm{pp}$.

Ротот, S. (2000): «Mobilités en Europe. Étude de deux réseaux migratoires roumains», Sociologie Româneasca, 2: 97-115 http://www.sociologieromaneasca.ro/2000/ articole/sr2000.2-a5.pdf

Ротот, S. (2007): Vivre à l'Est, travailler à l'Ouest: les routes roumaines de l'Europe, París, l'Harmattan, 226 p.

PuMARES, P. (2005): «Distribución territorial y movilidad interprovincial de la población marroquí en España», Quaderni del Dipartimento per lo Studio delle Società Mediterranee, 32: 203-230.

Pumares, P.; García, A. y AsEnsio, A. (2006): La movilidad laboral y geográfica de la población extranjera en España, Madrid, OPI, Ministerio de Trabajo y Asuntos Sociales, Documentos, 10, p. 217.

RECAÑO, J. (2002): «La movilidad geográfica de la población extranjera en España: un fenómeno emergente», Cuadernos de Geografía, 74: 135-156.

- (2004): «Migraciones internas y distribución espacial de la población española». En Leal, Jesús (coord.): Informe sobre la situación demográfica en España, Madrid, Fundación Fernando Abril Martorell, pp. 187-228.

- (2006): «Los intercambios poblacionales entre las regiones españolas». En Fernández Cordón, Juan Antonio y Leal, Jesús (coord.): Análisis territorial de la demografía española, Madrid, Fundación Fernando Abril Martorell, pp. 273-318. 
REHER, D.-S. - dir- (2008): Informe Encuesta Nacional de Inmigrantes (ENI-2007), Documentos de Trabajo, Instituto Nacional de Estadística, Madrid, 153 p.

- y REQuenA, Miguel (2008): «El cuestionario de la Encuesta Nacional de Inmigrantes 2007, Índice. Revista de Estadística y Sociedad, 30: 13-15.

REQUES, P. y Cos, O. de (2004): «De lo glogal a lo local: repercusiones geodemográficas de la inmigración en España», Economistas, 99: 48-61.

SANDU, D. - dir. - (2009): Comunidades rumanas en España, Bucarest, Fundación Soros, 148 p. + apéndice, http://www.osf.ro/ro/program articol.php?articol=151\#

VIRUELA, R. (2002): «La nueva corriente inmigratoria de Europa del Este», Cuadernos de Geografía, 72: 231-258.

- (2006): «Inmigrantes rumanos en España. Aspectos territoriales y procesos de sustitución laboral», Scripta Nova. Revista Electrónica de Geografía y Ciencias Sociales, http://www.ub.es/geocrit/sn/sn-222.htm

- (2008): «Población rumana y búlgara en España: evolución, distribución geográfica y flujos migratorios», Cuadernos de Geografía, 84: 169-194.

\section{Apéndice}

Migración interior de la población rumana, 2001-2007

\begin{tabular}{|c|c|c|c|c|c|c|c|c|c|c|c|c|c|c|}
\hline & \multirow{2}{*}{\multicolumn{2}{|c|}{$\begin{array}{c}\text { Migración } \\
\text { intraprovincial }\end{array}$}} & \multicolumn{12}{|c|}{ Migración interprovincial } \\
\hline & & & \multicolumn{4}{|c|}{ Inmigración } & \multicolumn{4}{|c|}{ Emigración } & \multicolumn{2}{|c|}{ Saldo } & \multicolumn{2}{|c|}{$\begin{array}{c}\% \text { prov. } \\
\text { vecina }(1)\end{array}$} \\
\hline & Total & Tasa (2) & p. vecina & a otras & Total & Tasa (2) & p. vecina & a otras & Total & Tasa (2) & $\begin{array}{c}\text { Inmigr.- } \\
\text { Emigr. }\end{array}$ & Tasa (2) & Inmigr. & Emigr. \\
\hline Total & 131.004 & 49,9 & 37.283 & 61.472 & 98.755 & 37,6 & 37.283 & 61.472 & 98.755 & 37,6 & 0 & 0,0 & 37,8 & 37,8 \\
\hline Álava & 142 & 23,8 & 252 & 160 & 412 & 69,2 & 273 & 129 & 402 & 67,5 & 10 & 1,7 & 61,2 & 67,9 \\
\hline Albacete & 847 & 30,7 & 821 & 987 & 1.808 & 65,6 & 1.123 & 1.252 & 2.375 & 86,2 & -567 & $-20,6$ & 45,4 & 47,3 \\
\hline Alicante & 4.269 & 42,5 & 1.057 & 4.158 & 5.215 & 52,0 & 1.056 & 2.120 & 3.176 & 31,7 & 2.039 & 20,3 & 20,3 & 33,2 \\
\hline Almería & 2.231 & 26,6 & 334 & 1715 & 2.049 & 24,5 & 386 & 2.508 & 2.894 & 34,6 & -845 & $-10,1$ & 16,3 & 13,3 \\
\hline Asturias & 705 & 75,9 & 60 & 636 & 696 & 74,9 & 35 & 407 & 442 & 47,6 & 254 & 27,3 & 8,6 & 7,9 \\
\hline Ávila & 227 & 40,0 & 496 & 119 & 615 & 108,3 & 349 & 227 & 576 & 101,4 & 39 & 6,9 & 80,7 & 60,6 \\
\hline Badajoz & 783 & 67,4 & 488 & 563 & 1.051 & 90,5 & 509 & 630 & 1.139 & 98,1 & -88 & $-7,6$ & 46,4 & 44,7 \\
\hline Baleares* & 1.463 & 49,7 & & 1.653 & 1.653 & 56,2 & & 816 & 816 & 27,7 & 837 & 28,4 & 0,0 & 0,0 \\
\hline Barcelona & 8.203 & 61,4 & 1.187 & 3.723 & 4.910 & 36,7 & 1.334 & 2.362 & 3.696 & 27,6 & 1.214 & 9,1 & 24,2 & 36,1 \\
\hline Burgos & 735 & 37,0 & 340 & 882 & 1.222 & 61,5 & 348 & 784 & 1.132 & 57,0 & 90 & 4,5 & 27,8 & 30,7 \\
\hline Cáceres & 203 & 62,0 & 146 & 348 & 494 & 150,8 & 154 & 422 & 576 & 175,9 & -82 & $-25,0$ & 29,6 & 26,7 \\
\hline Cádiz & 284 & 50,7 & 142 & 307 & 449 & 80,1 & 194 & 270 & 464 & 82,8 & -15 & $-2,7$ & 31,6 & 41,8 \\
\hline Cantabria & 936 & 72,9 & 240 & 682 & 922 & 71,8 & 181 & 417 & 598 & 46,6 & 324 & 25,2 & 26,0 & 30,3 \\
\hline Castellón & 9.693 & 38,3 & 1.732 & 3.674 & 5.406 & 21,4 & 2.174 & 3.346 & 5.520 & 21,8 & -114 & $-0,5$ & 32,0 & 39,4 \\
\hline Ceuta* & 0 & 0,0 & & 1 & 1 & 15,4 & & 3 & 3 & 46,2 & -3 & $-46,2$ & 0,0 & 0,0 \\
\hline Ciudad Real & 1.681 & 25,4 & 1.032 & 1.696 & 2.728 & 41,3 & 907 & 2.756 & 3.663 & 55,4 & -935 & $-14,1$ & 37,8 & 24,8 \\
\hline Córdoba & 522 & 33,0 & 548 & 638 & 1.186 & 75,1 & 605 & 831 & 1.436 & 90,9 & -250 & $-15,8$ & 46,2 & 42,1 \\
\hline Coruña & 357 & 75,6 & 46 & 332 & 378 & 80,1 & 71 & 465 & 536 & 113,6 & -158 & $-33,5$ & 12,2 & 13,2 \\
\hline Cuenca & 1.707 & 42,9 & 1.652 & 617 & 2.269 & 57,1 & 1.725 & 1.173 & 2.898 & 72,9 & -629 & $-15,8$ & 72,8 & 59,5 \\
\hline Gerona & 2.159 & 55,2 & 650 & 1.172 & 1.822 & 46,6 & 451 & 509 & 960 & 24,5 & 862 & 22,0 & 35,7 & 47,0 \\
\hline Granada & 998 & 34,9 & 366 & 572 & 938 & 32,8 & 441 & 1.059 & 1.500 & 52,4 & -562 & $-19,6$ & 39,0 & 29,4 \\
\hline Guadalajara & 1.834 & 51,3 & 3.512 & 656 & 4.168 & 116,5 & 1.606 & 768 & 2.374 & 66,4 & 1.7948 & 50,2 & 84,3 & 67,6 \\
\hline Guipuzcoa & 716 & 99,5 & 128 & 862 & 990 & 137,6 & 177 & 318 & 495 & 68,8 & 495 & 68,8 & 12,9 & 35,8 \\
\hline Huelva & 857 & 50,4 & 224 & 923 & 1.147 & 67,5 & 392 & 1.327 & 1.719 & 101,1 & -572 & $-33,6$ & 19,5 & 22,8 \\
\hline Huesca & 1.117 & 53,9 & 814 & 931 & 1.745 & 84,3 & 626 & 791 & 1.417 & 68,4 & 328 & 15,8 & 46,6 & 44,2 \\
\hline Jaén & 279 & 33,7 & 202 & 582 & 784 & 94,6 & 183 & 631 & 814 & 98,2 & -30 & $-3,6$ & 25,8 & 22,8 \\
\hline
\end{tabular}




\begin{tabular}{|c|c|c|c|c|c|c|c|c|c|c|c|c|c|c|}
\hline León & 318 & 67,5 & 91 & 393 & 484 & 102,8 & 104 & 473 & 577 & 122,5 & -93 & $-19,7$ & 18,8 & 18,0 \\
\hline Lérida & 3.384 & 62,8 & 1.017 & 1.980 & 2.997 & 55,6 & 1.158 & 1.220 & 2.378 & 44,1 & 619 & 11,5 & 33,9 & 48,7 \\
\hline Lugo & 145 & 100,7 & 41 & 146 & 187 & 129,9 & 69 & 197 & 266 & 184,7 & -79 & $-54,9$ & 21,9 & 25,9 \\
\hline Madrid & 47.680 & 58,1 & 4.440 & 8.667 & 13.107 & 16,0 & 7.564 & 13.819 & 21.383 & 26,1 & -8.276 & $-10,1$ & 33,9 & 35,4 \\
\hline Málaga & 1.088 & 42,1 & 307 & 1.237 & 1.544 & 59,7 & 229 & 715 & 944 & 36,5 & 600 & 23,2 & 19,9 & 24,3 \\
\hline Melilla* & 0 & 0,0 & & 7 & 7 & 466,7 & & 5 & 5 & 333,3 & 2 & 133,3 & 0,0 & 0,0 \\
\hline Murcia & 1.249 & 45,9 & 680 & 1.213 & 1.893 & 69,5 & 447 & 917 & 1.364 & 50,1 & 529 & 19,4 & 35,9 & 32,8 \\
\hline Navarra & 1.590 & 94,1 & 546 & 586 & 1.132 & 67,0 & 380 & 525 & 905 & 53,6 & 227 & 13,4 & 48,2 & 42,0 \\
\hline Ourense & 143 & 82,4 & 53 & 123 & 176 & 101,4 & 20 & 177 & 197 & 113,5 & -21 & $-12,1$ & 30,1 & 10,2 \\
\hline Palencia & 105 & 63,1 & 77 & 128 & 205 & 123,1 & 78 & 107 & 185 & 111,1 & 20 & 12,0 & 37,6 & 42,2 \\
\hline Palmas & 470 & 50,9 & 25 & 456 & 481 & 52,1 & 17 & 325 & 342 & 37,0 & 139 & 15,0 & 5,2 & 5,0 \\
\hline Pontevedra & 300 & 54,0 & 69 & 295 & 364 & 65,5 & 54 & 286 & 340 & 61,2 & 24 & 4,3 & 19,0 & 15,9 \\
\hline Rioja & 1.856 & 38,6 & 562 & 746 & 1.308 & 27,2 & 513 & 797 & 1.310 & 27,2 & -2 & 0,0 & 43,0 & 39,2 \\
\hline Salamanca & 377 & 63,2 & 79 & 385 & 464 & 77,8 & 79 & 396 & 475 & 79,6 & -11 & $-1,8$ & 17,0 & 16,6 \\
\hline Segovia & 323 & 57,8 & 427 & 169 & 596 & 106,7 & 383 & 349 & 732 & 131,1 & -136 & $-24,4$ & 71,6 & 52,3 \\
\hline Sevilla & 920 & 75,4 & 663 & 915 & 1.578 & 129,4 & 390 & 697 & 1.087 & 89,1 & 491 & 40,3 & 42,0 & 35,9 \\
\hline Soria & 85 & 30,0 & 200 & 313 & 513 & 181,3 & 105 & 233 & 338 & 119,4 & 175 & 61,8 & 39,0 & 31,1 \\
\hline Sta. Cruz & 473 & 64,0 & 17 & 534 & 551 & 74,6 & 25 & 289 & 314 & 42,5 & 237 & 32,1 & 3,1 & 8,0 \\
\hline Tarragona & 4.069 & 44,3 & 1.955 & 2.040 & 3.995 & 43,5 & 1.412 & 1.129 & 2.541 & 27,7 & 1.454 & 15,8 & 48,9 & 55,6 \\
\hline Teruel & 1.076 & 42,2 & 982 & 338 & 1.320 & 51,8 & 1.143 & 557 & 1.700 & 66,7 & -380 & $-14,9$ & 74,4 & 67,2 \\
\hline Toledo & 4.697 & 41,5 & 3.674 & 1.450 & 5.124 & 45,2 & 3.022 & 2.745 & 5.767 & 50,9 & -643 & $-5,7$ & 71,7 & 52,4 \\
\hline Valencia & 9.742 & 60,6 & 2.745 & 5.639 & 8.384 & 52,2 & 2.000 & 3.815 & 5.815 & 36,2 & 2.569 & 16,0 & 32,7 & 34,4 \\
\hline Valladolid & 705 & 44,5 & 238 & 767 & 1.005 & 63,5 & 233 & 994 & 1.227 & 77,5 & -222 & $-14,0$ & 23,7 & 19,0 \\
\hline Vizcaya & 2.297 & 107,5 & 321 & 788 & 1.109 & 51,9 & 289 & $\overline{416}$ & 705 & 33,0 & 404 & 18,9 & 28,9 & 41,0 \\
\hline Zamora & 141 & 80,3 & 99 & 256 & 355 & 202,3 & 120 & 272 & 392 & 223,4 & -37 & $-21,1$ & 27,9 & 30,6 \\
\hline Caragoza & 4.823 & 30,0 & 1.506 & 3.312 & 4.818 & 30,0 & 2.149 & 3.696 & 5.845 & 36,4 & -1.027 & $-6,4$ & 31,3 & 36,8 \\
\hline
\end{tabular}

Fuente: INE, Estadística de Variaciones Residenciales [www.ine.es]. Elaboración propia.

(1) Porcentaje con respecto a la emigración (inmigración) a (de) provincias vecinas con respecto al total de la migración interprovincial

(2) La tasa expresa el número total de movimientos entre 2001 y 2007 por cada mil rumanos empadronados a mediados del periodo.

* No se han considerado en los desplazamientos entre provincias vecinas.

\section{RESUMEN}

En los primeros años del siglo XXI, la población rumana residente en España experimenta un aumento espectacular. En la actualidad, es el colectivo extranjero con mayor número de efectivos y el que alcanza mayor dispersión geográfica. El objetivo de este artículo es analizar la estructura territorial de las migraciones interiores protagonizadas por los rumanos entre 2001 y 2007. Para ello se han utilizado los datos de la Estadística de Variaciones Residenciales, que elabora el Instituto Nacional de Estadística con las altas y bajas de Padrón de Habitantes. Destaca el fuerte incremento de la movilidad, el predominio de los desplazamientos de corta distancia, los que tienen lugar dentro de la misma provincia y entre provincias vecinas, y el protagonismo de Madrid y el litoral mediterráneo en la redistribución interprovincial de migrantes. La movilidad geográfica está motivada por la búsqueda de mejores condiciones de vida, se relaciona con el mercado de trabajo y de la vivienda, las redes sociales y la actitud de la sociedad y de las autoridades locales hacia los extranjeros. 


\title{
PALABRAS CLAVE
}

Inmigración rumana, España, movilidad interna, redistribución geográfica.

\begin{abstract}
In the early twenty-first century, the Romanian population in Spain showed a spectacular increase. It is now the largest group of foreign population and also the most geographically dispersed. The aim of this paper is to analyze the spatial structure of internal migration by Romanians between 2001 and 2007. Data from the Statistics of Residential Variations produced by the National Institute of Statistics (INE, Instituto Nacional de Estadística) which registers municipal residents was used. The results show the sharp increase of mobility, the predominance of short-distance movements, which take place within the same province and neighbouring provinces, and the role of Madrid and the Mediterranean coast in the redistribution of interprovincial Romanian population in Spain. Geographic mobility is due to the pursuit of better living conditions, which is related to the labour market and housing, as well as social networks and the attitudes of society and local authorities towards foreigners.
\end{abstract}

\section{KEY WORDS}

Romanian immigration, Spain, internal mobility, geographical redistribution. 